\title{
Candida Albicans Virulence Factors and Its Pathogenicity
}

\author{
Mariana Henriques *(1) and Sónia Silva \\ CEB-Centre of Biological Engineering, University of Minho, 4710-057 Braga, Portugal; soniasilva@deb.uminho.pt \\ * Correspondence: mcrh@deb.uminho.pt
}

Citation: Henriques, M.; Silva, S. Candida Albicans Virulence Factors and Its Pathogenicity. Microorganisms 2021, 9, 704. https://doi.org/ 10.3390/microorganisms 9040704

Received: 15 March 2021

Accepted: 25 March 2021

Published: 29 March 2021

Publisher's Note: MDPI stays neutral with regard to jurisdictional claims in published maps and institutional affiliations.

Copyright: (c) 2021 by the authors. Licensee MDPI, Basel, Switzerland. This article is an open access article distributed under the terms and conditions of the Creative Commons Attribution (CC BY) license (https:// creativecommons.org/licenses/by/ $4.0 /)$.
Candida albicans lives as commensal on the skin and mucosal surfaces of the genital, intestinal, vaginal, urinary, and oral tracts of $80 \%$ of healthy individuals. An imbalance between the host immunity and this opportunistic fungus may trigger mucosal infections followed by dissemination via the bloodstream and infection of the internal organs. Candida albicans is considered the most common opportunistic pathogenic fungus in humans and a causative agent of $60 \%$ of mucosal infections and $40 \%$ of candidemia cases [1,2]. Several virulence factors are known to be responsible for $C$. albicans infections, such as adherence to host and abiotic medical surfaces, biofilm formation as well as secretion of hydrolytic enzymes. Moreover, C. albicans resistance to traditional antimicrobial agents, especially azoles, is well known, especially when Candida cells are in biofilm form.

This Special Issue covers different aspects related to $C$. albicans pathogenicity, virulence factors, the mechanisms of antifungal resistance and the molecular pathways of host interactions. The review by Ciurea et al. [3] presents the virulence factors of the most important Candida species, namely $C$. albicans, contributing to a better understanding of the onset of candidiasis and raising awareness of the overly complex interspecies interactions that can change the outcome of the disease. The article by Yoo et al. [4] provides a comprehensive review about the association between C. albicans and the cases of persistent or refractory root canal infections. It also points out the importance of alternative intracanal medicaments such as chlorhexidine gel or human beta defensin-3 (HBD3), Ca-Si-based obturating materials, and microsurgical procedures. Zambom et al. [5] presented a review on the promising alternatives of the use of antifungal peptides (AFPs) from the Histatin family (like histatin-5) and nanoparticles (NPs) for the treatment of candidiasis. The article reveals how nanotechnology can allow the application of AFPs and NPs for the treatment of Candida infections. Rosati et al. [6] provided an overview of the current understanding of the host immune response in vulvovaginal candidiasis (VVC) pathogenesis and suggests that a tightly regulated fungus-host-microbiota interplay might exert a protective role against recurrent Candida infections. The review by Satala et al. [7] describes the importance of $C$. albicans cell wall proteins not only as a protective envelope but also as a point of contact with the human host, providing a dynamic response to the constantly changing environmental infection niches. The sixth review article in the Special Issue (Costa-deOliveira et al. [8]) describes the main factors that are involved in antifungal resistance and tolerance in patients with C. albicans bloodstream infections. Azoles are widely used drugs in the treatment of candidiasis, which target the lanosterol $14 \alpha$-demethylase (Erg11p) encoded by the ERG11 gene, therefore the data of Suchodolski et al. [9] showed that targeted gene disruption of ERG11 can result in resistance to ergosterol-dependent drugs (azoles and amphotericin B). They suggested that this new insight into intracellular processes under Erg11p inhibition may lead to a better understanding of the indirect effects of azoles on C. albicans cells and the development of new treatment strategies for resistant infections. In addition, the same authors [10] proposed a new method for the detection of cell membrane depolarization/permeabilization in C. albicans using the potentiometric zwitterionic dye di-4-ANEPPS. The data presented by Caldara et al. [11] suggest that nortriptyline can be considered a "new" antimicrobial drug with great potential for application in in vivo C. albicans infection models. Therapies targeted to fungal biofilms, mainly against the 
matrix, and therapies that do not induce microbial resistance are relevant. N-acetylcysteine (NAC), a mucolytic agent, has shown antimicrobial action. Nunes et al. [12] evaluated the effect of NAC against fluconazole-susceptible and -resistant $C$. albicans and the results revealed that high concentrations of NAC had similar fungistatic effects against both strains, while a low concentration showed the opposite result. Ubiquinones (UQ) are intrinsic lipid components of many membranes and Pathirana et al. [13] provided specific exam of Ubiquinones (UQ) and proved the significance of UQ side chains in farnesol production and resistance quite apart from being an electron carrier in the respiratory chain of $C$. albicans cells. MAP kinase (MAPK) signal transduction pathways facilitate the sensing and adaptation of $C$. albicans cells to external stimuli and control the expression of key virulence factors such as the yeast-to-hypha transition, the biogenesis of the cell wall, and the interaction with the host. Correia et al. [14] demonstrated that the four MAPK pathways play distinct roles in adhesion, epithelial damage, invasion, and cell wall remodelling that may contribute to the pathogenicity of $C$. albicans. The behaviour of $C$. albicans on simulated human body fluids (artificial saliva and urine) at different values of $\mathrm{pH}$ ( $\mathrm{pH} 5.8$ and 7) was analysed by Barbosa et al. [15]. The authors demonstrated that C. albicans presents high plasticity and adaptability to different human body fluids, namely saliva and urine. Interestingly, Tseng et al. [16] showed that unlike C. albicans, the C. tropicalis ROB1 deletion strain did not cause a significant reduction in biofilm formation, suggesting that the biofilm regulatory circuits of the two species are divergent.

Overall, the 14 papers published in this Special Issue nicely illustrate why the C. albicans continues to be one of the most common opportunistic pathogenic fungi in humans and highlights the importance of focusing research on understanding the mechanisms of antifungal resistance and its pathogenicity.

Funding: This research received no external funding.

Acknowledgments: We would like to thank all the authors for their interesting contributions to this Special Issue. We are grateful to all the reviewers for their insightful and helpful recommendations. We would also like to thank the Microorganisms editorial office staff for all their assistance and the opportunity to organize this Special Issue.

Conflicts of Interest: The author declares no conflict of interest.

\section{References}

1. Gonçalves, B.; Ferreira, C.; Alves, C.T.; Henriques, M.; Azeredo, J.; Silva, S. Vulvovaginal candidiasis: Epidemiology, microbiology, and risk factors. Crit. Rev. Microbiol. 2016, 42, 905-927. [CrossRef] [PubMed]

2. $\quad$ Pappas, P.G.; Lionakis, M.S.; Arendrup, M.C.; Ostrosky-Zeichner, L.; Kullberg, B.J. Invasive candidiasis. Nat. Rev. Dis. Primers 2018, 4, 18026. [CrossRef] [PubMed]

3. Ciurea, C.; Kosovski, I.; Mare, A.; Toma, F.; Pintea-Simon, I.; Man, A. Candida and Candidiasis-Opportunism Versus Pathogenicity: A Review of the Virulence Traits. Microorganisms 2020, 8, 857. [CrossRef] [PubMed]

4. Yoo, Y.; Kim, A.; Perinpanayagam, H.; Han, S.; Kum, K. Candida albicans Virulence Factors and Pathogenicity for Endodontic Infections. Microorganisms 2020, 8, 1300. [CrossRef] [PubMed]

5. Reis Zambom, C.; Henrique da Fonseca, F.; Santesso Garrido, S. Bio-and Nanotechnology as the Key for Clinical Application of Salivary Peptide Histatin: A Necessary Advance. Microorganisms 2020, 8, 1024. [CrossRef] [PubMed]

6. Rosati, D.; Bruno, M.; Jaeger, M.; ten Oever, J.; Netea, M. Recurrent Vulvovaginal Candidiasis: An Immunological Perspective. Microorganisms 2020, 8, 144. [CrossRef] [PubMed]

7. Satala, D.; Karkowska-Kuleta, J.; Zelazna, A.; Rapala-Kozik, M.; Kozik, A. Moonlighting Proteins at the Candidal Cell Surface. Microorganisms 2020, 8, 1046. [CrossRef] [PubMed]

8. Costa-de-Oliveira, S.; Rodrigues, A. Candida albicans Antifungal Resistance and Tolerance in Bloodstream Infections: The Triad Yeast-Host-Antifungal. Microorganisms 2020, 8, 154. [CrossRef] [PubMed]

9. Suchodolski, J.; Krasowska, A. Plasma Membrane Potential of Candida albicans Measured by Di-4-ANEPPS Fluorescence Depends on Growth Phase and Regulatory Factors. Microorganisms 2019, 7, 110. [CrossRef] [PubMed]

10. Suchodolski, J.; Muraszko, J.; Bernat, P.; Krasowska, A. A Crucial Role for Ergosterol in Plasma Membrane Composition, Localisation, and Activity of Cdr1p and H+-ATPase in Candida albicans. Microorganisms 2019, 7, 378. [CrossRef] [PubMed]

11. Caldara, M.; Marmiroli, N. Known Antimicrobials Versus Nortriptyline in Candida albicans: Repositioning an Old Drug for New Targets. Microorganisms 2020, 8, 742. [CrossRef] [PubMed] 
12. Nunes, T.; Rosa, L.; Vega-Chacón, Y.; Mima, E. Fungistatic Action of N-Acetylcysteine on Candida albicans Biofilms and Its Interaction with Antifungal Agents. Microorganisms 2020, 8, 980. [CrossRef] [PubMed]

13. Pathirana, R.; Boone, C.; Nickerson, K. Longer Ubiquinone Side Chains Contribute to Enhanced Farnesol Resistance in Yeasts. Microorganisms 2020, 8, 1641. [CrossRef] [PubMed]

14. Correia, I.; Prieto, D.; Román, E.; Wilson, D.; Hube, B.; Alonso-Monge, R.; Pla, J. Cooperative Role of MAPK Pathways in the Interaction of Candida albicans with the Host Epithelium. Microorganisms 2020, 8, 48. [CrossRef] [PubMed]

15. Barbosa, A.; Araújo, D.; Ribeiro, E.; Henriques, M.; Silva, S. Candida albicans Adaptation on Simulated Human Body Fluids under Different pH. Microorganisms 2020, 8, 511. [CrossRef] [PubMed]

16. Tseng, Y.; Chen, Y.; Hou, C.; Deng, F.; Liang, S.; Hoo, S.; Hsu, C.; Ke, C.; Lin, C. Evaluation of Biofilm Formation in Candida tropicalis Using a Silicone-Based Platform with Synthetic Urine Medium. Microorganisms 2020, 8, 660. [CrossRef] [PubMed] 